\title{
UMA DISCUSSÃO ACERCA DO CONCEITO DE BIBLIOTECA COMUNITÁRIA
}

\section{Elisa Campos Machado}

\section{Resumo:}

O trabalho tem por objetivo analisar as diversas formas de emprego do termo "biblioteca comunitária" na literatura da área de Biblioteconomia e sua relação com os tipos de bibliotecas caracterizadas pela área. A partir de uma revisão da literatura abre-se uma discussão acerca dos aspectos que diferenciam as bibliotecas comunitárias das bibliotecas públicas e populares. Concluí que as bibliotecas comunitárias, em função de suas particularidades, se apresentam hoje na sociedade brasileira, como um novo tipo de biblioteca, pois são criadas seguindo os princípios da autonomia, da flexibilidade e da articulação local. Ressalta ainda que sua forma de atuação esta muito mais ligada à ação cultural do que aos serviços de organização e tratamento da informação. Por fim, apresenta uma definição para o termo "biblioteca comunitária”.

\section{Palavras-chave:}

Biblioteca comunitária; Tipologia de bibliotecas

\section{A DISCUSSION ABOUT THE COMMUNITY LIBRARY CONCEPT}

\begin{abstract}
:
The purpose of this paper is to analyze the term "community library" in the librarianship literature and its relationship with the kinds of libraries identified by the area. The literature review proposes a discussion about the differences between the public and popular libraries. The conclusion is that community library, due to its particularity, represents today in the Brazilian society a new type of library, because they are organized according with principles of autonomy, flexibility and local network. The paper also highlights that participation is more linked to the cultural action rather than to the organization services and information treatment. Finally, presents a definition for “community library”.
\end{abstract}

\section{Keywords:}

Community library; Typology of library 


\section{INTRODUÇÃO}

A linguagem, como uma das formas de expressão da humanidade, é considerada um sistema de comunicação criado pelo homem e que tem como princípio a sua constante reconstrução. À medida que a sociedade se transforma, percebemos na linguagem o surgimento de novos termos e expressões. Algumas áreas do conhecimento, como a Lingüística e a Semiótica, dedicam seus estudos a acompanhar de forma rigorosa esse fenômeno. Se, por um lado, podemos dizer que essa flexibilidade e reconstrução permanente são ricas, pois estão sempre criando novos sentidos para a vida e para as relações, por outro lado, esse fato muitas vezes causa problemas sérios de sentido e compreensão do mundo.

Só para se ter uma noção das dificuldades que enfrentadas, podemos citar o caso da própria Ciência da Informação, em que os problemas em relação à linguagem se iniciam na definição do termo ${ }^{1}$ “informação”, o que passa a ser um grande obstáculo até mesmo para a área se firmar no mundo científico.

Com relação ao termo "biblioteca comunitária", percebemos a dificuldade na sua definição, pois ele vem sendo empregado, pela sociedade em geral, como sinônimo de biblioteca pública e biblioteca popular, sendo que, de modo geral, o mesmo ocorre no contexto acadêmico. Partindo do princípio de que é importante a utilização de termos claros e significativos dentro de uma área de pesquisa, acreditamos ser importante fazer uma reflexão sobre suas formas de emprego e sua relação com os tipos de bibliotecas caracterizados pela Biblioteconomia.

Apesar da escassez de literatura sobre o assunto, não podemos dizer que o emprego do termo biblioteca comunitária é recente. Na literatura estrangeira, identificamos autores utilizando essa denominação para se referir àquelas bibliotecas que tem um trabalho ativo junto a sua comunidade. Na maioria dos casos, essas bibliotecas poderiam ser caracterizadas, segundo a tipologia biblioteconômica, como bibliotecas públicas, pois possuem o mesmo objetivo, ou seja, democratizar o acesso ao livro e à informação para a comunidade local. O mesmo acontece com o uso do termo bibliotecas populares.

\footnotetext{
${ }^{1}$ Termo é aqui entendido como uma unidade de comunicação que representa o conceito. 


\section{O EMPREGO DO TERMO}

$\mathrm{Na}$ literatura nacional, encontramos poucos trabalhos que tratam do assunto, aparentemente o fato dessas bibliotecas surgirem de modo espontâneo na comunidade não colabora para ampliar o registro sobre essas ações.

Segundo Almeida Junior (1997), o termo biblioteca comunitária é citado pela primeira vez na literatura brasileira da área em 1978, por Carminda Nogueira de Castro Ferreira ao se referir à experiência americana do início do século passado que tratava da integração da biblioteca pública com a escolar ${ }^{2}$.

Todêska Badke apresenta um dos primeiros relatos na literatura nacional sobre constituição de bibliotecas comunitárias, o caso da biblioteca do Parque Residencial Laranjeiras, localizado no município da Serra, ao Norte da Grande Vitória, no Espírito Santo. Apesar de afirmar que é uma biblioteca comunitária, essa experiência é denominada pela autora como uma biblioteca popular, pois considera popular "o que é feito pelo povo e para o povo, compreendendo por isso sua efetiva participação” (BADKE, 1984, p. 18).

Ainda segundo Badke, a biblioteca popular caracteriza-se por surgir da vontade, necessidade e trabalho de uma comunidade; ela emerge do esforço de pessoas que lutam juntas, tendo como principal objetivo realizar um trabalho baseado na proposta de transformar a realidade vigente. Estas bibliotecas, normalmente, aparecem em bairros onde vivem pessoas de uma classe social menos favorecida, com experiências de lutas sociais (BADKE, 1984, p. 18).

Diferentemente, Gorosito López (2003) apresenta a experiência da instalação de uma biblioteca comunitária no povoado “18 de Septiembre”, da cidade de San Fernando, Chile, cuja idéia nasceu da luta do povo contra a exclusão social e como reivindicação do direito à informação. O uso do termo biblioteca comunitária pelo autor e pelo grupo

\footnotetext{
${ }^{2}$ Na cidade de São Paulo foram criadas as bibliotecas dos Centros de Educação Unificados (CEUs) com as mesmas características da experiência americana analisada por Ferreira, porém, as bibliotecas dos CEUs não são identificadas como bibliotecas comunitárias e sim públicas, principalmente por estarem vinculadas diretamente a um órgão governamental.
} 
idealizador do projeto é empregado com o mesmo significado que Todeska Badke dá ao termo biblioteca popular - do povo e para o povo.

O mesmo se dá no trabalho de Geraldo Prado (2004), ao apresentar uma análise e avaliação dos impactos gerados a partir da experiência de criação da Biblioteca Comunitária Maria das Neves Prado no pequeno povoado de São José do Paiaiá, no município de Nova Soure, região do semi-árido baiano. Nesse caso, a biblioteca foi criada pelo autor, porém, a partir de ações pedagógicas foi sendo incorporada pela comunidade. É importante destacar que a população desta cidade, em sua grande maioria, nunca tinha tido acesso a um livro.

Já Almeida e Machado (2006), ao apresentar um relato sobre o encontro "Bibliotecas comunitárias e populares: diálogos com a universidade” iniciam seu texto contextualizando e evidenciando as dificuldades no emprego do termo. Todas as experiências apresentadas naquele evento são identificadas como bibliotecas comunitárias e são evidenciadas como resultado de iniciativas autônomas, quando muito apoiadas por agentes sociais que não são da comunidade local e sim de organizações do Terceiro Setor. Fazem parte desse relato as seguintes experiências: Biblioteca comunitária do Projeto Casulo, Biblioteca comunitária “Livro-pra-que-te-quero", Biblioteca comunitária UNAS de Heliópolis, Biblioteca comunitária Solano Trindade da Associação Biblioteca Zumaluma.

Cabe destacar o trabalho sobre a história das bibliotecas comunitárias na Escócia, apresentado por John Crawford no 68th IFLA Council and General Conference de 2002. O autor esclarece que estes espaços eram também conhecidos como "library society” pelo fato dos membros ou associados se inscreverem e pagarem taxas como num clube. Segundo Crawford, a origem das bibliotecas comunitárias na Escócia data o século 17 e sua concepção ficou enraizada na cultura e valores intelectuais do país de maneira que até hoje as bibliotecas públicas conservam um forte cunho democrático, visto que são administradas a partir de comitês compostos por membros da comunidade local. O autor finaliza seu trabalho afirmando que foi o legado das bibliotecas comunitárias que deu a Escócia, condição de ser o primeiro país no mundo a ter políticas públicas nacionais para as bibliotecas públicas. Nesse caso fica evidente que o termo é empregado para 
identificar um tipo específico de bibliotecas que tinham características diferentes das atuais bibliotecas públicas.

No entanto, na maioria dos relatos de experiências em países desenvolvidos, tais como Estados Unidos da América (COLSON, 1975; SUAIDEN, 1995), Irlanda (MARTIN, 1975), Inglaterra (FINNEGAN, 1975), Austrália (THOMAS, 1975) e mesmo Suécia, (SUAIDEN, 1995) de modo geral os autores utilizam o termo bibliotecas comunitárias (Community Library) para qualificar uma biblioteca pública, ou seja, vinculada a órgãos públicos e localizada em bairro periférico de grandes centros urbanos ou na zona rural. É o caso das experiências descritas por William Martin acerca das bibliotecas nas regiões periféricas da cidade de Belfast, na Irlanda. As abordagens desses relatos são, em sua maioria, referentes ao trabalho, organização e implantação de serviços informacionais e de leitura para comunidades específicas, caracterizadas como excluídas ou em situação de risco, tais como: comunidades de presidiários, comunidades formadas por pessoas com necessidades especiais, desempregados, moradores de rua, iletrados e imigrantes.

Fazendo uma comparação entre relatos atuais e históricos podemos concluir que o conceito de biblioteca comunitária utilizados nos dias de hoje, nos países chamados de primeiro mundo, é diferente daquele usado por Crawford sobre o surgimento das bibliotecas na Escócia.

Temos notícias da existência de bibliotecas comunitárias na Europa em geral, advindas de ações de grupos de imigrantes que, em função das dificuldades lingüísticas e da necessidade de preservar suas culturas, criam suas bibliotecas comunitárias, porém, não encontramos relatos técnicos que pudessem validar cientificamente esta questão.

Retomando para a esfera nacional, recentemente percebemos que a Universidade vem estimulando a produção de Trabalhos de Conclusão de Curso (TCCs) sobre o assunto, o que demonstra uma crescente curiosidade por parte de jovens alunos de cursos de Biblioteconomia e Ciência da Informação em entender qual o papel das bibliotecas comunitárias na democratização da informação, nos processos de desenvolvimento local e de transformação social. Vale destacar o trabalho de Célia Barbosa de Sá que faz um estudo de caso das bibliotecas comunitárias da Associação Comunitária Monte Azul na

(c) Revista Digital de Biblioteconomia e Ciência da Informação,Campinas, v.7, n. 1, p. 80-94, jul./dez. 2009- ISSN: 1678-765X. 
cidade de São Paulo, SP. Nos TCCs analisados (SÁ, 2007; FACCIONI, 2003) ficou evidente a dificuldade dos alunos em relação à conceituação da biblioteca comunitária.

\section{A BIBLIOTECA COMUNITÁRIA E A TIPOLOGIA DA ÁREA}

De modo geral, as bibliotecas atendem as demandas de suas comunidades e são caracterizadas por elas, ou seja, pelo seu público. A biblioteca universitária é criada por lei federal, independente de ser vinculada a uma instituição de ensino superior pública ou privada, atende prioritariamente a comunidade de docentes, estudantes e funcionários que a integram, enquanto que a biblioteca especializada está necessariamente atrelada a uma instituição e atende às demandas informacionais do grupo de técnicos e especialistas vinculados formalmente a essa instituição.

Esses dois tipos de bibliotecas estão ligados a comunidades discursivas que, segundo Swales (1990 apud NASCIMENTO; MARTELETO 2004), possuem metas comuns, mecanismos participativos, trocas de informação, estilos específicos, terminologia especializada e alto nível de especialização.

As bibliotecas públicas são espaços públicos. No Brasil são criadas por lei estaduais e municipais e possuem vínculo direto com um órgão governamental, estado, município ou federação, os quais respondem por sua manutenção por meio de recursos humanos, financeiros e materiais. Atendem as demandas da população que reside ou freqüenta a região em que está localizada. São criadas para atender as necessidades informacionais de uma ou mais comunidades, ou seja, seu público é heterogêneo, o que significa que pode trabalhar com várias comunidades discursivas, as quais nem sempre possuem todas as características apresentadas por Swales, tais como alto nível de especialização, terminologia especializada, ou mecanismos participativos.

Alguns estados e municípios brasileiros, com o objetivo de aproximar as bibliotecas públicas de suas comunidades, passaram a denominá-las como bibliotecas populares, é o caso, por exemplo, dos municípios do Rio de Janeiro e de Niterói. Nesses casos, ao substituir pública por popular, parece-nos que o estado espera, com isso, fazer com que o imaginário da sociedade capture esse termo e o incorpore ao espaço público da biblioteca, 
como uma qualidade de experiências sociais, políticas e culturais. No entanto, essas bibliotecas continuaram as mesmas, ou seja, as mudanças ficaram apenas no campo semântico e não foram suficientes para garantir a sua incorporação no campo da prática ou da ação. Nesse sentido poderíamos concluir que essas mudanças são resultado de uma ação populista e não genuinamente popular. Para Marilena Chauí

\begin{abstract}
a tradição populista, mais forte no final dos anos de 1950 e início de 1960, pretende que o órgão público de cultura tenha um papel pedagógico sobre as massas populares para, depois de transformá-la, devolvê-la em sua 'verdade verdadeira' ao 'povo' (CHAUI, 2006, p. 67).
\end{abstract}

Já a escolha do termo popular pela sociedade em geral, provavelmente surja a partir de uma associação com o pensamento de Antonio Gramsci. O popular na cultura, segundo a perspectiva gramsciana, significa

[...] a transfiguração expressiva de realidades vividas, conhecidas, reconhecidas e identificáveis, cuja interpretação pelo intelectual, pelo artista e pelo povo coincide. Essa transfiguração pode ser realizada tanto pelos intelectuais 'que se identificam com o povo' como por aqueles que saem do próprio povo, na qualidade de seus intelectuais orgânicos (CHAUÍ, 2006, p. 20).

Ao associar o popular à biblioteca, acreditamos que os autores e os atores responsáveis por esse tipo de projeto esperam elaborar uma outra idéia da biblioteca pública.

Almeida Junior (1997), em seu livro Bibliotecas Públicas e Bibliotecas Alternativas, resultado de sua dissertação de mestrado, apresenta um estudo caracterizando e identificando as diferenças entre a biblioteca pública, a biblioteca popular e a biblioteca comunitária. Nesse estudo, o autor parte do histórico do surgimento das bibliotecas públicas para fazer o paralelo com as novas iniciativas, por ele denominadas, bibliotecas alternativas. No terceiro capítulo de seu livro, Almeida Junior extrai e discute as tentativas de definição do termo biblioteca comunitária apresentadas por alguns autores, tais como Ida Stumpf, Sarti, Guiraldelli e Vicentin, Todeska Badke e por fim, conclui que em relação ao uso do termo na literatura, este é usado como forma de amenizar as idéias que acompanhavam as propostas de bibliotecas populares. Quanto a tipologia, conclui que a biblioteca comunitária não pode ser caracterizada como um tipo diferente de 
biblioteca, pois, de modo geral, possui os mesmos objetivos e normalmente oferece os mesmos serviços que a biblioteca pública.

O adjetivo comunitário estaria sendo empregado com o intuito de destacar essa proposta de outras tantas existentes, tornando-a mais atraente, inclusive para a sociedade que, em função dessa nova designação, pode imaginá-la tratando-se de uma instituição diferente da biblioteca pública sobre a qual já possui um estereótipo formado. Assim a biblioteca comunitária passaria para a sociedade, por uma nova entidade, não carregando preconceitos e idéias preconcebidas que prejudicariam sua atuação (ALMEIDA JUNIOR, 1997, p. 107).

Sobre as bibliotecas populares é importante resgatar o estudo sociológico realizado por Gilda Verri (1996) sobre as bibliotecas populares da cidade de Recife no período de 1930 a 1964. Segundo a autora, a idéia e criação de bibliotecas populares foi um projeto político das elites brasileiras, fortemente vinculado à concepção da Educação Popular da década de 1920. A autora destaca que Recife seguiu as experiências de bibliotecas populares defendidas pelo Rio de Janeiro, São Paulo e Belo Horizonte, que tinham como padrão o modelo americano.

Outra contribuição importante sobre o assunto é a pesquisa histórica realizada por Patrícia Raffaini (2001) sobre o Departamento de Cultura de São Paulo, suas políticas culturais e as ações dos intelectuais na época. A pesquisa restringe-se ao período entre 1935 a 1938, em que Mário de Andrade foi diretor do Departamento e nos apresenta o forte papel educativo implementado por ele com o objetivo de conscientizar e criar cidadãos transformadores da vida pública. Em relação às bibliotecas

o projeto que deveria ser desenvolvido compreendia uma rede de bibliotecas: uma biblioteca central, voltada à pesquisa e não circulante; bibliotecas infantis; bibliotecas populares de bairro, em que a população poderia emprestar as mais diversas obras e uma biblioteca circulante montada em uma caminhonete adaptada (RAFFAINI, 2001, p. 67).

Nos dois trabalhos, fica claro que a biblioteca popular proposta na época referia-se às bibliotecas de bairro ou distritais. Hoje a cidade de São Paulo, possui um total de 81 bibliotecas públicas, incluindo as localizadas na região central da cidade - Mário de Andrade, Monteiro Lobato e Sérgio Milliet - e as de bairro, que incluem as bibliotecas dos Centros Educacionais Unificados (CEUs). 
Dentro deste contexto cabe destacar o fato da Biblioteca da Universidade Federal de São Carlos (UFSCar) utilizar por denominação o termo biblioteca comunitária ${ }^{3}$. Segundo eles esta opção se deu pelo fato de ser uma biblioteca aberta a comunidade local, ou seja, além de atender alunos, professores e funcionários atende também a comunidade externa. Para nós isso é um exemplo de uso indevido do termo, visto que está se caracteriza prioritariamente como uma biblioteca universitária e tem, como todas as demais bibliotecas deste tipo, a função de oferecer serviços de extensão à comunidade. Neste caso consideramos que houve uma inversão de valores o que só colabora para vulgarizar o termo.

\section{O QUE ENTENDEMOS POR BIBLIOTECA COMUNITÁRIA}

Acreditamos que ao abrir um espaço para refletir sobre o conceito da biblioteca comunitária no contexto atual, estamos enfrentando o que Edgar Morin (2002, p. 14) chama de "supremacia do conhecimento fragmentado de acordo com as disciplinas". Segundo o autor, esse conhecimento fragmentado “deve ser substituído por um modo de conhecimento capaz de apreender os objetos em seu contexto, sua complexidade, seu conjunto”. Tendo em vista que estes espaços, comumente denominados como bibliotecas comunitárias multiplicam-se pelo país, assim como Morin, consideramos ser preciso “rever nossas teorias e idéias, em vez de deixar o fato novo entrar à força na teoria incapaz de recebê-lo” (2002, p. 30).

Nesse sentido, pensando a partir da tipologia da área, entendemos os argumentos de Almeida Junior em relação à semelhança entre a proposta da biblioteca pública e da biblioteca comunitária, pois o autor estabelece sua reflexão a partir do espaço, do acervo, do público e dos serviços que a unidade informacional oferece. No entanto, se a observarmos em seu contexto, levando em conta toda a complexidade que a envolve e considerarmos outros aspectos, podemos identificar particularidades que as distinguem, tais como:

\footnotetext{
${ }^{3}$ Biblioteca Comunitária UFSCar (http://www.bco.ufscar.br/htdocs/) 
1. a forma de constituição: são bibliotecas criadas efetivamente pela e não para a comunidade, como resultado de uma ação cultural.

2. a perspectiva comum do grupo em torno do combate à exclusão informacional como forma de luta pela igualdade e justiça social.

3. o processo participativo gerando articulação local e forte vínculo com a comunidade.

4. a referência espacial: estão, em geral, localizadas em regiões periféricas.

5. o fato de não serem instituições governamentais, ou com vinculação direta aos Municípios, Estados ou Federação.

Baseando-se ainda nos estudos realizados por Macedo e Spinelli (1987), Cunali e Branco (2002) e Almeida e Machado (2006), elaboramos o quadro apresentado a seguir para melhor visualização as diferenças identificadas por nós entre a biblioteca pública e a comunitária.

Quadro I - Quadro comparativo entre Bibliotecas Públicas e Bibliotecas Comunitárias.

\begin{tabular}{|l|c|c|}
\hline \multicolumn{1}{|c|}{ Características } & Bibliotecas Públicas & Bibliotecas Comunitárias $^{\text {Projeto político social }}$ \\
\hline Fundamentação & Projeto técnico ${ }^{4}$ & Dada pelo grupo \\
\hline Legitimidade & Dada pelas leis & $\begin{array}{c}\text { Vinculada a um grupo de pessoas, } \\
\text { podendo ou não ser parceira ou ter } \\
\text { apoio de órgão públicos e privados. }\end{array}$ \\
\hline Estrutura & Vinculada a órgão governamental & Mínima - Flexível \\
\hline $\begin{array}{l}\text { Equipe Interna - } \\
\text { Constituição }\end{array}$ & $\begin{array}{c}\text { Fúgida - altamente hierarquizada } \\
\text { Pública, alocados no equipamento } \\
\text { independentemente do seu vínculo } \\
\text { local. }\end{array}$ & Membros da comunidade. \\
\hline Equipe interna - Postura & Dependência & Autonomia \\
\hline
\end{tabular}

Por essas particularidades, de forma complementar ao pensamento de Almeida Junior, consideramos que a biblioteca comunitária como se apresenta hoje na sociedade

\footnotetext{
${ }^{4} \mathrm{O}$ termo projeto técnico é aqui empregado levando em conta as considerações feitas por Francis Woff (2007, p. 73) onde o técnico refere-se a ações puramente administrativas e burocráticas que buscam soluções racionais e simples para problemas sociais. Por exemplo, as bibliotecas públicas no Brasil, definem seus horários utilizando um método puramente técnico - das 8 hs às $17 \mathrm{hs}$ de $2^{\mathrm{a}}$. a 6 a . feira.

${ }^{5} \mathrm{O}$ projeto político social é aqui usado no sentido de um projeto que prioriza as necessidades sociais na sua concepção. Neste caso, o exemplo acima teria que encontrar outras possibilidades de horário para atender a população que no horário comercial não pode freqüentar a biblioteca.
}

(C) Revista Digital de Biblioteconomia e Ciência da Informação,Campinas, v.7, n. 1, p. 80-94, jul./dez. 2009- ISSN: 1678-765X. 
brasileira, pode ser considerada um outro tipo de biblioteca, pois vem sendo criada seguindo os princípios da autonomia, da flexibilidade e da articulação local, o que amplia as possibilidades de atuação e de inserção na sociedade. Outro fator que nos leva a considerá-las diferente é pela forma de atuação estar muito mais ligada a ação cultural do que aos serviços de organização e tratamento da informação. Estes princípios podem ser considerados qualidades essenciais destas bibliotecas, os quais as diferenciam das demais, tornando-as únicas e que, se retirados, destroem sua essência.

Parece-nos que o que Bauman (2003) diz sobre o significado e os sentimentos que o termo comunidade carrega são potencializados pelo termo biblioteca, já que este também opera no imaginário da sociedade como um espaço carregado de cultura. O termo comunidade é usado, nesse caso, como um qualificador para identificar espaços de acesso à informação, leitura e ao livro, fortemente vinculados ou direcionados a grupos específicos dentro de um contexto de necessidades socioculturais.

Chaúi (2006, p. 62), ao refletir sobre a expressão “nacional-popular”, alerta para o fato de que "justamente porque os termos não cessam de ser definidos e articulados de maneira diferentes em diferentes condições históricas, a imaginação ideológica procura fixá-la como se fossem entidades positivas”. Acreditamos que, na opção pelo uso da denominação bibliotecas comunitárias o mesmo se dá; nesse caso ele não carrega apenas significados e sentimentos, carrega também ideologias. O mesmo ocorre com “popular”, também um termo qualificador para a biblioteca e usado para afirmar o desejo de trabalhar, ou seja, oferecer serviços, para várias camadas da população. Porém, em função do tempo, espaço e das ideologias, os grupos tendem a utilizar um ou outro termo qualificador.

Entendemos que o conceito de biblioteca comunitária, no Brasil remete a uma categoria de entidades que possui o mesmo significado, ou seja, espaços físicos abertos ao público local, de acesso à informação e às diversas formas de leitura, onde a ação cultural é fortemente implementada. 


\section{CONCLUSÃO}

Para nós, o emprego do termo biblioteca comunitária é mais apropriado para identificar o que consideramos ser empreendimentos sociais que surgem do desejo e da necessidade de um determinado grupo de pessoas em ter acesso ao livro, à informação e à prática da leitura num real exercício de cidadania. Em outras palavras, podemos identificar as bibliotecas comunitárias como projetos vinculados a um grupo particular de pessoas, sem vínculo direto com o Estado, que têm como objetivo atender esse mesmo grupo, os quais possuem os mesmos problemas, os mesmos interesses e a sua própria cultura, seja esse um grupo de especialistas em paleontologia, um grupo de imigrantes, ou ainda um grupo de moradores de uma comunidade considerada de risco. Estas pessoas juntas constituemse como agentes coletivos, que por meio de práticas sociais interferem numa realidade agindo de maneira transformadora.

Com base na análise sobre o emprego do termo e levando-se em consideração os cinco aspectos acima apresentados, para nós o termo biblioteca comunitária pode ser definido como: um projeto social que tem por objetivo, estabelecer-se como uma entidade autônoma, sem vínculo direto com instituições governamentais, articuladas com as instâncias públicas e privadas locais, lideradas por um grupo organizado de pessoas, com o objetivo comum de ampliar o acesso da comunidade à informação, à leitura e ao livro, com vistas a sua emancipação social.

\section{REFERÊNCIAS}

ALMEIDA, Maria Christina Barbosa; MACHADO, Elisa Campos. Biblioteca comunitária em pauta. In: ENCONTROS COM A BIBLIOTECA, 2006, São Paulo. Bibliotecas comunitárias e populares: diálogo com a universidade, São Paulo : Itaú Cultural, $2006 . \quad$ Disponível em: $<$ http://www.itaucultural.org.br/index.cfm?cd_pagina=2405 > Acesso em: 04/01/2007.

ALMEIDA JUNIOR, Oswaldo Francisco de. Bibliotecas públicas e bibliotecas alternativas. Londrina : Editora UEL, 1997. 
BADKE, Todêsca. Biblioteca popular: uma experiência no bairro das Laranjeiras.

Palavra-Chave, São Paulo, n.4, p.18-9, maio, 1984.

BAUMAN, Z. Comunidade: a busca por segurança no mundo atual. Rio de Janeiro : Zahar, 2003.

CHAUÍ, Marilena de Souza. Cidadania cultural: o direito à cultura. São Paulo : Fundação Perceu Abramo, 2006.

COLSON, John C. The United States: an historical critique. In: MARTIN, William (Ed.)

Library services to the disadvantaged. London : Clive Bingley, 1975. p. 32-46.

CRAWFORD, John. The community library in scottish history. Trabalho apresentado ao 68th IFLA Council and General Conference, Glasgow, 2002. Disponível em: $<$ http://209.85.165.104/search?q=cache:pYKw0HrDd10J:www.ifla.org/IV/ifla68/papers/ 063-111e.pdf+community+library+in+scottish+history\&hl=pt-BR\&ct=clnk\&cd=1>. Acesso em: 10 jan. 2008.

CUNALI, Marina; BRANCO, Cecília. A dinâmica do cenário das bibliotecas públicas de São Paulo. São Paulo : SMC/DBP, 2002. CD-ROM.

FACCION JUNIOR, Carlos Magno. Biblioteca comunitária: uma alternativa entre a biblioteca pública e a biblioteca escolar. 2005. Trabalho de Conclusão de Curso-Escola de Biblioteconomia, Universidade Federal do Estado do Rio de Janeiro, Rio de Janeiro, 2005.

FINNEGAN, Gerry. Public library and community development. In: MARTIN, William (Ed.) Library services to the disadvantaged. London : Clive Bingley, 1975. p. 32-46.

GOROSITO LÓPEZ, Antonio. La biblioteca comunitária: uma experiência de organización social, educativa y cultural. Biblios, ano 4, n.15, p.35-40, Jun. 2003. 
MACEDO, Neusa Dias de; SPINELLI, Laila Gebara. Subsídios para a caracterização da biblioteca pública. Revista Brasileira de Biblioteconomia e Documentação, São Paulo, v. 20, n.1/4, p.71-77, jan./dez. 1987.

MARTIN, William (Ed.) Library services to the disadvantaged. London : Clive Bingley, 1975.

MORIN, Edgar. Os sete saberes necessários à educação do futuro. 6. ed. São Paulo : Cortez, 2002.

NASCIMENTO, Denise Morado; MARTELETO, Regina Maria. A “informação construída” nos meandros dos conceitos da teoria social de Pierre Bordieu. Datagramazero. Ciência da Informação, São Paulo, v.5, n.5, out. 2004. Disponível em: <http://dgz.org.br/out04/Art_05.htm> Acesso em: 10 jan. 2008.

PRADO, Geraldo Moreira. Da história latente à história verdadeira: uma experiência piloto com a biblioteca comunitária. In: FORÓ SOCIAL DE INFORMACIÓN, DOCUMENTACIÓN Y BIBLIOTECAS, 1., 2004, Buenos Aires. Anais eletrônico ... Disponível em: <http://209.85.165.104/search?q=cache:XcrJg5zoCwEJ:www.inforosocial.net/ponencias/ eje04/30.pdf+hist\%C3\%B3ria+latente+\%C3\%A0+hist\%C3\%B3ria+verdadeira\&hl=ptBR\&ct=clnk\&cd=1>. Acesso em: 10 jan. 2008.

RAFFAINI, Patrícia Tavares. Esculpindo a cultura na forma Brasil: o Departamento de Cultura de São Paulo (1935-1938). São Paulo : Humanitas, 2001.

SÁ, Célia Barbosa de. Entre o ideal e o real: as bibliotecas da Associação Comunitária Monte Azul. 2007. Trabalho de Conclusão de Curso-Escola de Comunicação e Artes, Universidade de São Paulo, São Paulo, 2007.

SUAIDEN, Emir. Biblioteca pública e a informação à comunidade. São Paulo : Global, 1995. 
THOMAS, T. Library services to immigrants in Austrália. In: MARTIN, William (Ed.)

Library services to the disadvantaged. London : Clive Bingley, 1975. p. 161-175.

VERRI, Gilda Maria Whitaker. Templários da ausência em bibliotecas populares.

Recife : UFPE, 1996.

\section{Elisa Campos Machado}

Doutoranda em Ciência da Informação pela Escola de Comunicação e Artes da Universidade de São Paulo (ECA/USP) sob orientação do Prof. Dr. Waldomiro Vergueiro e docente do Departamento de Estudos Processos Biblioteconômicos da Escola de Biblioteconomia da Universidade Federal do Estado do Rio de Janeiro (DEPB/EB/UNIRIO).

emachad02005@gmail.com

Recebido em: 25/02/2008

Aceito para publicação em: jan/2009 